\title{
College Student Attendance at Sporting Events and the Relationship Between Sport Team Identification and Social Psychological Health
}

\author{
Daniel L. Wann, Emily Brame, Mary Clarkson, Danielle Brooks, \\ and Paula J. Waddill \\ Murray State University
}

\begin{abstract}
Consistent with the Team Identification-Social Psychological Health Model (Wann, 2006a), past research indicates college students' levels of identification with university teams is positively correlated with social psychological health. The current investigation was designed to examine how attendance may impact this relationship. The sample contained 148 college students who completed a questionnaire packet assessing identification with their school's men's basketball team, amount of attendance at the team's games, and two measures of social well-being (loneliness and collective self-esteem). Regression analyses revealed that level of team identification (i.e., private involvement), but not attendance (i.e., public involvement), accounted for a significant proportion of unique variance in well-being. Therefore, it appears that private involvement with a college sport team is more strongly associated with college students' social well-being than is public involvement.
\end{abstract}

There is little argument to the notion that sport has become an important component of life on most college campuses. Certainly, this is true for studentathletes. In fact, social scientists from many disciplines have generated a large body of empirical and theoretical work targeting athletes, including research on racial and gender issues (Brooks \& Althouse, 1993; Lopiano, 1993), anxiety and coping (Holm, Beckwith, Ehde, \& Tinius, 1996; Kimball \& Freysinger, 2003), and predictors of academic success (Richards \& Aries, 1999; Sedlacek, \& AdamsGaston, 1992). However, university athletics can be equally vital and important to students because supporting university teams and attending sporting events have become an integral part of college life for many of these individuals. Indeed, attendance figures at National Collegiate Athletic Association (NCAA) athletic events are staggering. For example, estimates from the 2006-2007 season reveal that, at the Division I level, over 42 million fans attended NCAA football contests while more than 34 millions fans attended men's and women's basketball games ("List of Sports," 2008). Millions more attended Division II and Division III con-

The authors are with the Department of Psychology at Murray State University, Murray, KY, 42071. 
tests and more still attended nonrevenue sporting events. While many of these spectators were likely not college students, many of these sport consumers were.

The impact of collegiate athletics on the lives and experiences of college students is not limited to game attendance. Rather, research indicates that there are "identifiable and measurable benefits (academic and psychological)" (Wann \& Robinson, 2002, p. 37) for college students who become involved with their school's sport teams as a fan. For instance, consider the work of Schurr, Wittig, Ruble, and Henriksen (1993). These authors reasoned that attendance at sporting events would lead to social integration benefits for the student attendees and, consequently, result in peer networks, which could lead to concrete advantages in terms of grade point average and graduation rates. To test their hypothesis, Schurr and colleagues compared students attending and not attending their college's athletic events. As expected, those in the attending group had a significantly higher mean grade point average (2.55) and a higher graduation rate (.64) than those students in the nonattending group, who had a mean grade point average of 2.36 and a graduation rate of .48. It is also important to mention that the two groups did not differ, on the basis of high school grade point averages and college entrance test scores, in their expected college performance. Thus, the attending students were not simply better students; rather, they appear to have received benefits via their interest in and involvement with their school's sport program as fans (although definitive conclusions about causation are not warranted due to the nonexperimental nature of the study).

A related study was conducted by Wann and Robinson (2002). These researchers argued that college students' interest in and involvement with their university's athletic teams should be related to the fans' integration into and perceptions of their school. Specifically, they hypothesized that fans' levels of identification with their school's sport teams (i.e., their psychological connection to the team, see Wann, Melnick, Russell, \& Pease, 2001) should lead to increased social capital (i.e., social connections) with other students. The increased social capital should, in turn, result in a greater desire to remain at and graduate from their current institution and lead to positive perceptions of the university. A pair of studies examining over 300 university students confirmed expectations. As hypothesized, levels of team identification (for football, basketball, and the university sport program as a whole) were significantly and positively correlated with levels of involvement with the university, persistence toward graduation, satisfaction with the university, enjoyment of the university, and perceptions that the university had met expectations.

The aforementioned literature suggests that college students may be able to gain tangible benefits (e.g., produce higher grade point averages) via an identification with their university's sports teams and that universities may benefit as well (e.g., gain higher levels of persistence and involvement among students). However, another line of research reveals that, in addition to the previously described benefits, students may also receive a psychological benefit as a consequence of their team identification because higher levels of identification are related to positive levels of social well-being. This pattern of effects is detailed in Wann's (2006a) Team Identification-Social Psychological Health Model (TI-SPHM). According to this framework, identification with a sport team leads to increased social connections with others. 
Two types of connections are expected to be facilitated via team identificationthose that are enduring and others that are temporary. Enduring connections involve the associations with other fans that are generated when one resides in the community in which the team in question is found (e.g., a student fan of the Kansas Jayhawks who lives on the University of Kansas campus in Lawrence). Temporary connections occur when persons who do not reside in the team's community find themselves, from time to time, in the company of other fans of the team (e.g., a student fan of the Kansas Jayhawks who lives in Manhattan, Kansas, home of the rival Kansas State Wildcats, but who watches Kansas University games on television with several friends who are also fans of the University of Kansas team). The enduring and temporary connections are then predicted to lead to increased social psychological health (e.g., less loneliness, increased social self-esteem) both at the trait level (for enduring connections) and at the state level (for temporary connections). The relationship between social connections and social well-being is expected be moderated by threats to social identity (e.g., poor team performance, player arrests) and attempts to cope with those threats (e.g., biased attributions and perceptions of players).

Support for the TI-SPHM is quite strong (see Wann, 2006a, for an overview). Further, longitudinal cross-lagged methodologies suggest a causal pattern in which identification directly impacts subsequent social well-being. However, of particular note for the current research is the fact that most of the research supporting the model has tested college students. For instance, research indicates that, among college student samples, identifying with a university sport teams does indeed lead to increased social capital (Wann, Polk, \& Weaver, 2008). Furthermore, a number of studies have documented the positive relationship between team identification and social well-being among college student populations. For example, college students with higher levels of identification with their school's sport teams (relative to students with lower levels of identification) report greater levels of satisfaction with their social lives (Wann \& Pierce, 2005), lower levels of loneliness (Wann, Walker, Cygan, Kawase, \& Ryan, 2005), more frequent positive emotions and less frequent negative emotions (Branscombe \& Wann, 1991), lower levels of alienation (Branscombe \& Wann, 1991), higher levels of selfesteem (Branscombe \& Wann, 1991; Wann, 1994; Wann, Inman, Ensor, Gates, \& Caldwell, 1999; Wann \& Pierce, 2005; Wann et al., 2005), higher levels of vigor (Wann et al., 1999), higher levels of extroversion (Wann, Dunham, Byrd, \& Keenan, 2004), and more trust in others (Wann \& Polk, 2007). Also consistent with the TI-SPHM, research indicates that college students experience a threat to their social identity when their school's team performs poorly (Hirt, Zillmann, Erickson, \& Kennedy, 1992). And finally, college students develop and use a wide range of strategies to help them cope with failures by their school's teams (End, Birchmeier, \& Mueller, 2004). For instance, following a loss by their university's teams, highly identified college students report self-serving attributions (Wann \& Schrader, 2000), biased predictions and recollections of their team's performances (Wann \& Dolan, 1994a), biased evaluations of fellow ingroup fans and rival outgroup fans (Wann \& Dolan, 1994b), and systematic uses of pessimism (Wann \& Grieve, in press; Wann, Grieve, Waddill, \& Martin, in press). 
While the research detailed above reveals an impressive body of literature on the relationship between college team identification and well-being, as well as support for the TI-SPHM (Wann, 2006a), one area that has not been examined concerns the impact of game attendance on the aforementioned pattern of effects. Research on the relationship between psychological health and identification with other (i.e., nonsport team) groups reveals that attendance can be an important factor. Consider, for example, research on the relationship between religion and well-being in which positive correlations have consistently been noted (Baumeister \& Leary, 1995; Diener, Suh, Lucas, \& Smith, 1999; Witter, Stock, Okun, \& Haring, 1985). In that research, a distinction is often made between public and private involvement (Levin, Markides, \& Ray, 1996). Public religious involvement concerns public religious participation, such as attendance at church functions, while private religious involvement concerns one's "religious sense of selfidentity" (Idler, 1987, p. 231).

As it relates to the sport fan experiences of college students, public involvement would include attendance at the university's sporting events while private involvement concerns one's level of team identification (i.e., his or her psychological connection to the team). While some may wonder about the relevance of religious research for sport, these two institutions are not entirely dissimilar and have often drawn comparisons (Higgs, 1995; Hoffman, 1992; Wann et al., 2001). For instance, public involvement in both sport (e.g., game attendance, watching a broadcast at a bar) and religion (e.g., church attendance, Bible study classes) may take many forms. Further, the different forms can vary widely in cost for both institutions, ranging from free or nearly free (watching sport on television at home with friends; attending church socials) to highly expensive activities (attending a championship game; traveling to a sacred religious site far from one's home).

Although previous research indicates that both private and public forms of religious involvement may be related to well-being (Idler, 1987), it is difficult to say how this study will translate to the world of sport fandom. Research suggests that attendance may indeed be important. Fans report more positive levels of state psychological health while at a sporting event relative to later on at their place of residence (Wann, Martin, Grieve, \& Gardner, in press). However, Wann's model predicts that it is the enduring connections generated by the fan's team identification that lead to the well-being effects. These connections can be found in many areas and are not limited to the sporting events themselves. Rather, college students can find themselves with other fans of the team in many locations other than the arena, such as their dorm, the student union, in the library, at local businesses, at work, and so forth.

Therefore, at this point it is difficult to predict which form of fan involvement would be more closely associated with well-being. As a consequence, this investigation did not offer a specific prediction but instead examined the following research question: "Which form of sport fan involvement, public (i.e., game attendance) or private (i.e., team identification) accounts for the greater proportion of unique variance in the social psychological health of college students?" The reader is reminded that the comparison was between different forms of involvement — namely, public involvement via attendance and private involvement 
via team identification. We are not implying that these are the only forms of public and private involvement. Rather, these were chosen to better mirror research on religious involvement.

\section{Method}

\section{Participants and Design}

The original sample of participants consisted of 212 college students receiving extra course credit in exchange for their participation. However, 64 of these persons $(30 \%)$ had not been at the target university (Murray State University) for the entire previous year and, thus, could not have attended all of the team's games. These individuals were therefore removed from the data set, resulting in a final sample of 148 (57 male; 91 female) participants. These respondents had a mean age of 21.63 years $(S D=4.13$; range $=18-47)$.

\section{Materials and Procedure}

Upon entering the testing session and providing their consent, groups of participants were handed a questionnaire packet containing three sections. The first section requested information on gender, age, whether the participant had attended Murray State University for the entire previous year, and the question, "On average, how many Murray State University men's basketball home games do you attend each season (from 0 games to 15 games)?" The attendance item assessed fans' level of public involvement with the team.

The second section contained the Sport Spectator Identification Scale (SSIS; Wann \& Branscombe, 1993) as an assessment of private involvement. The SSIS contains seven Likert-scale items with response options ranging from 1 (low identification) to 8 (high identification). Thus, higher numbers represented greater levels of identification. The SSIS was selected for use in the current study because this inventory has been used successfully in previous investigations of the wellbeing of sport fans (e.g., Branscombe \& Wann, 1991; Wann, 1994; Wann \& Pierce, 2005) and this scale has strong reliability (e.g., the Cronbach alpha in past research has exceeded .90, see Wann, Dimmock \& Grove, 2003, Wann \& Pierce, 2005) and validity among college student populations (see Wann \& Branscombe, 1993; Wann et al., 2001). Participants were specifically told to target their university's men's basketball team (Murray State University) when completing the SSIS. A sample item from this scale read, "How important to you is it that the Murray State University men's basketball team wins?"

The third section of the protocol contained two reliable and valid instruments assessing social well-being (i.e., "the appraisal of one's circumstance and functioning in society," Keyes, 1998, p. 122). First, this section contained the 16-item Collective Self-esteem Scale (CSE; Luhtanen \& Crocker, 1991). Collective (or social) self-esteem concerns one's critical evaluations of his or her group memberships (Luhtanen \& Crocker, 1992) and thus, it is an important component of social well-being. Response options to the CSE ranged from 1 (strongly disagree) to 7 (strongly agree) with greater numbers reflecting more positive levels of collective self-esteem. Wann et al. (2003) report a Cronbach's reliability alpha of .83 
for the CSE. A sample item from this scale reads, "In general, I'm glad to be a member of the social groups I belong to." Second, participants completed the 20-item the UCLA Loneliness Scale (UCLAL: Russell, Peplau, \& Cutrona, 1980), an instrument assessing trait levels of loneliness (another key component of social well-being). Response options to the UCLALS ranged from 1 (never) to 4 (often) and responses were coded so that higher numbers reflected more positive social well-being (i.e., lower levels of loneliness). Wann et al. (2003) found a Cronbach's alpha coefficient of .88 for the UCLALS. A sample item contained in the UCLALS reads, "There are people I feel close to."

These two instruments (the CSE and UCLALS) were selected for several reasons. First, each measures a different component of social well-being rather than personal well-being, which is appropriate for tests of Wann's (2006a) model and similar research on group identity (Rubin \& Hewstone, 1998). ${ }^{1}$ Second, these measures had been successfully used in past work examining the psychological health of fans (e.g., Wann, 2006b; Wann et al., 2005). And third, both scales assess trait levels of well-being. Because we were interested in the consequences of enduring social connections, assessments of trait well-being were more appropriate than assessment of state well-being (see Wann, 2006a). After completing and returning their questionnaire packet-typically requiring about 15 minutesparticipants were debriefed and excused from the testing session.

\section{Results}

Items contained in each scale were summed to establish scale scores for each measure. The means, standard deviations, ranges, and Cronbach reliability alphas for each scale are listed in Table 1. Responses to the collective self-esteem scale and the loneliness inventory were correlated $(r=.58, p<.001)$. Thus, consistent with past methodologies (e.g., Wann, 2006b; Wann, Keenan, \& Page, in press) and to streamline the analyses, scores on the self-esteem and loneliness scales were converted to $z$ scores and combined to form a single index of social psychological health (i.e., social psychological health index $=$ collective self-esteem scale $z$ score + loneliness inventory $z$ score). Correlations among the variables (i.e., average games attended, team identification, and social psychological health) appear in Table 1 Means, Standard Deviations, Ranges, and Cronbach
Reliability Alphas for the Dependent Measures

\begin{tabular}{lcccc}
\hline Measure & Mean & SD & Range & Alpha \\
\hline $\begin{array}{l}\text { Average games } \\
\text { attended }\end{array}$ & 2.96 & 3.50 & $0-15$ & - \\
$\begin{array}{l}\text { Team identification } \\
\quad \text { SSIS) }\end{array}$ & 22.51 & 12.66 & $7-53$ & .951 \\
$\begin{array}{l}\text { Collective self- } \\
\text { esteem }\end{array}$ & 90.07 & 12.22 & $52-112$ & .870 \\
$\begin{array}{l}\text { UCLA Loneliness } \\
\text { Scale }\end{array}$ & 68.12 & 9.98 & $30-80$ & .918 \\
\hline
\end{tabular}


Table 2 Simple Correlations Among the Variables

\begin{tabular}{lcc}
\hline & $\begin{array}{c}\text { Average games } \\
\text { attended }\end{array}$ & $\begin{array}{c}\text { Team identification } \\
\text { (SSIS) }\end{array}$ \\
\hline Team identification (SSIS) & $.62^{* * *}$ & - \\
Social psychological health & $.19^{*}$ & $.24^{* *}$ \\
\hline
\end{tabular}

$* p<.05 ; * * p<.01 ; * * * p<.001$.

Table 2. Both of the subject variables were significantly and positively correlated with the psychological health score as well as with each other. The high correlation between team identification and game attendance $(r=.62)$ is consistent with a large body of research indicating the strong relationship between these two variables (e.g., Fisher \& Wakefield, 1998; Wann, 2006c; Williamson, Zhang, Pease, \& Gaa, 2003).

To examine the research question asking, "Which form of sport fan involvement, public (i.e., game attendance) or private (i.e., team identification) would account for the greater proportion of unique variance in the social psychological health of college students," and to determine if attendance and team identification interacted, a moderated multiple regression analysis was conducted on the dependent variable of the social psychological health index score. Because the single predictors were $z$ scores, the interaction term was created as a product of those $z$ scores (following the recommendation of Aiken \& West, 1991). Using hierarchical regression, health score was first regressed on average games attended (public involvement) and level of team identification (SSIS scores; private involvement). In the second step, the interaction variable was introduced. The result of the analysis is presented in Table 3. Regressing the dependent variable on attendance and team identification resulted in an $R^{2}$ of $.061(p=.01)$. With respect to independent

Table 3 Moderated Multiple Regression Predicting Social Psychological Health

\begin{tabular}{lcccc}
\hline Predictor variable & $\boldsymbol{B}^{\mathbf{a}}$ & SE $\boldsymbol{B}$ & $\boldsymbol{t}$ & $\boldsymbol{\Delta R}^{\mathbf{2}}$ \\
\hline Step 1 & & & & $.061^{*}$ \\
attendance & .113 & .182 & .620 & \\
identification & .362 & .182 & $1.993^{*}$ & \\
Step 2 & & & & .000 \\
attendance x identification & -.020 & .156 & -.125 & \\
Overall $R$ & .248 & & & \\
Overall $R^{2}$ & .061 & & & \\
Adjusted $R^{2}$ & .042 & & & \\
Overall $F(3,144)$ & $3.14^{*}$ & & & \\
\hline
\end{tabular}

${ }^{a}$ Because all predictors are $z$ scores, the value of the raw coefficient $(B)$ represents the standardized solution.

$* p<.05$ 
contributions to social psychological health, although both variables were significantly correlated with health score, only team identification accounted for a significant unique proportion of the variance in social well-being $(t=1.99, p<.05)$ while average games attended did not $(t=.62, p=.62)$. Whereas the combined effect of the two predictor variables was significant, $F(2,145)=4.74, p=.01$, the introduction of the interaction term did not account for a significant additional proportion of variance in health score $\left(\Delta R^{2}=.00, p=.90\right)$. Thus, in the current investigation, the well-being of college students was associated with private involvement but not public involvement, and the effect of private involvement on well-being did not depend upon amount of public involvement.

\section{Discussion}

Previous research had indicated that college students with strong attachments to their university's sport teams (i.e., high level of team identification) report higher levels of social psychological health than students with lower levels of team allegiance (e.g., Branscombe \& Wann, 1991; Wann et al., 1999; Wann et al., 2004). This pattern of relationships is consistent with the Team Identification-Social Psychological Health Model (Wann, 2006a), which hypothesizes that higher levels of team identification result in valuable social connections with others that, in turn, facilitate well-being. The current investigation was designed to extend the previous work by examining the potential impact of game attendance. Because previous work had yet to examine this factor and because the TI-SPHM does not specifically address attendance, specific hypotheses were not generated. Rather, a research question asking, "Which form of sport fan involvement, public (i.e., game attendance) or private (i.e., team identification) would account for the greater proportion of unique variance in the social psychological health of college students" was examined. The data reported above on college students attending a midsouthern university (Division I, I-AA in football) revealed that both frequency of game attendance and level of team identification were positively and significantly correlated with social psychological health (as operationalized as social self-esteem and loneliness). However, regression analyses revealed that only team identification accounted for a significant unique proportion variance in well-being. Furthermore, attendance and identification did not interact. Thus, one can conclude that, for the current sample of college students, it was their private involvement with the team (level of identification) that was related to their social wellbeing, and not their public involvement (attendance). That is, the potential benefits to well-being that college students may gain from their associations with school teams does not appear simply to be a function of game attendance. Rather, it involves the degree to which the student feels a strong psychological connection to a team. Further, it is important to note that the data presented here are correlational in nature and, hence, definitive discussions of causality are not warranted. Although prior research using longitudinal designs and structural equation modeling does indeed suggest such a causal pattern (Wann, 2006b), it is premature to conclude that either attendance or identification causes well-being.

Nevertheless, the pattern of effects suggested by this research has important implications for athletic directors and university sport marketing professionals as 
well as university personnel involved with student retention, satisfaction, and well-being. New research suggests that university students are able to gain and maintain important social connections to others through their identification with their school's sport teams (Wann et al., 2008). Specifically, Wann and his colleagues have found that levels of team identification were positively related to percentage of friends following the team, number of friends following the team, and perceptions that the role of team follower helps form and maintain friendships (as this was only an initial test of this component of the model, more research is certainly warranted). Further, it is clear from research that these connections assist in the maintenance of social psychological health (Wann, 2006a; 2006b; Wann et al., 2008).

According to the results presented above, these social well-being benefits are not limited to those students who have the ability to attend athletic contests. This is fortunate because some students lack the ability or opportunity to attend their school's athletic events (e.g., conflicts with work, classes, parenting, and so forth). Yet these students may still reap the well-being benefits of team identification because they may gain valuable social capital in locations other than the arena (e.g., classrooms, dorms, etc.). Simply put, based on the data provided above, it is possible that all students stand to acquire a tangible boost in their social wellbeing via a university's sport program, regardless of their ability to attend the team's games. As noted, such a finding could be useful to university officials (e.g., athletic directors, coaches, faculty representatives) as they attempt to justify the importance and expense of their university's sport programs to various constituencies. That is, because the well-being benefits of identifying with a university sport team are not limited to those who can attend, all students (and other members of the local community) stand to benefit. This fact underscores one of the important psychological and societal benefits of university sport programs-namely, assistance in building "community" and the maintenance of well-being.

It is important to note that the social psychological health benefits of high levels of identification with university sport teams does not appear to be limited to popular "revenue-generating" sports (e.g., college football and basketball). Rather, consider the findings reported by Wann, Keenan, et al. (in press). These authors investigated the relationship between well-being and levels of identification with nonmarquee university sport teams. ${ }^{2}$ They found that, similar to prior work with popular university teams, levels of identification with nonmarquee sports were significantly and positively correlated with social well-being. Given that these sports often lack a large fan base and have lower levels of attendance, that research seems to fit well with the current investigation's finding that it was level of identification and not attendance that was uniquely predictive of well-being. That is, attendance was found to have little unique impact on well-being, which coincides well with the work indicating that levels of identification for sports with lower attendance numbers still have benefits for well-being.

Wann, Keenan, et al.'s (in press) research also found that college students who identified with more than one university team reported greater levels of wellbeing than persons who identified with only one. While the limit to this "add-on effect" is unknown (e.g., whether identifying with three teams is better than two, four better than three, and so on), their research indicates that there may be addi- 
tional psychological health benefits for identifying with more than one of a university's teams. Again, if there is a causal relationship here, this has important implications for a variety of university officials including athletic directors and retention officers. College students should be encouraged to identify with multiple teams rather than simply focus on a single team (similar to how they might identify with multiple campus organizations like social and honorary societies). This way, they likely will become even more integrated into campus life, gain additional social connections (i.e., a university's football fan base and basketball fan base do not contain identical individuals), and receive an even greater boost to their well-being.

Finally, a few limitations to the current investigation and suggestions for future research warrant mention. First, and perhaps foremost, this was only an initial test of the interrelationships among team identification (private involvement), attendance (public involvement), and social psychological well-being. It is imperative that researchers attempt to replicate the findings reported here. In addition, the current study examined attendance and identification only for one sport at one university. Subsequent investigations should examine different sports and different NCAA Divisions to test the generalizability of the findings reported here and perhaps include a larger sample. Future research might also want to consider assessing different forms of private and public involvement. With respect to private involvement, the current investigation assessed team identification via the SSIS (Wann \& Branscombe, 1993). However, there are other psychometrically sound measures for assessing identification. In particular, researchers may want to employ a multidimensional measure of team identification recently developed by Dimmock, Grove, and Eklund (2005). Unlike the unidimensional SSIS, their scale measures three different aspects of identification-cognitive/affective, personal evaluation, and other evaluation. Such a measure may give a more complete understanding of the relationships among identification, attendance, and wellbeing. As for assessments of public involvement, although game attendance is perhaps the most obvious form, other possibilities include attendance at pep rallies and tail-gating parties. Assessing these and other additional forms of public involvement would bolster the validity of the results reported here.

Finally, it is important to note that Wann's (2006a) theoretical framework specifically predicts a causal pattern in which the social connections generated by sport team identification directly facilitate social well-being. However, the vast majority of work to date exploring the model has been nonexperimental (i.e., correlational) in nature. Future research endeavors should implement experimental and longitudinal methodologies that would allow for definitive conclusions about the potential causal relationship between private involvement, public involvement, and social psychological health. Such research would be useful in determining the extent to which team identification is causally related to social well-being, test the reciprocity of the relationship, and examine the potential confounding impact of additional (i.e., "third") variables. Although initial investigations of the causal nature of these relationships have supported the causal pattern of effects predicted by the Team Identification-Social Psychological Health Model (Wann, 2006b), additional work of this type is needed, particularly on components of the model not previously examined, such as is the case with the current investigation. 


\section{Notes}

1. This is not meant to suggest that these are the only components of social well-being. Rather, several dimensions of social well-being have been suggested (Keyes, 1998), and research on the well-being of fans has examined many of these, including those assessed here, as well as others such as perceptions of trust (Wann \& Polk, 2007), extroversion (Wann et al., 2004), and satisfaction with one's social life (Wann \& Pierce, 2005).

2. Of course, teams that are popular and revenue generating differ from university to university. At the university tested in the Wann, Keenan, et al. (in press) research, the school's men's basketball team had a long tradition of success and fan support, but the football team and baseball team had experienced much lower levels of success and had much smaller fan bases. Thus, their research considered these sports to be nonrevenue generating and less popular.

\section{References}

Aiken, L.S., \& West, S.G. (1991). Multiple regression: Testing and interpreting interactions. Newbury Park, CA: Sage.

Baumeister, R.F., \& Leary, M.R. (1995). The need to belong: Desire for interpersonal attachments as a fundamental human motivation. Psychological Bulletin, 117, 497529.

Branscombe, N.R., \& Wann, D.L. (1991). The positive social and self-concept consequences of sport team identification. Journal of Sport and Social Issues, 15, 115-127.

Brooks, D., \& Althouse, R. (Eds.). (1993). Racism in college athletics. Morgantown, WV: Fitness Information Technology.

Diener, E., Suh, E.M., Lucas, R.E., \& Smith, H.L. (1999). Subjective well-being: Three decades of progress. Psychological Bulletin, 125, 276-302.

Dimmock, J.A., Grove, J.R., \& Eklund, R.C. (2005). Reconceptualizing team identification: New dimensions and their relationship to intergroup bias. Group Dynamics. Theory, Research, and Practice, 9, 75-86.

End, C., Birchmeier, Z., \& Mueller, D. (2004, September). How time and group reactions influence sport fans' online defensive reactions to various sources of identity threat. Paper presented at the annual meeting of the Association for the Advancement of Applied Sport Psychology, Minneapolis, MN.

Fisher, R.J., \& Wakefield, K. (1998). Factors leading to group identification: A field study of winners and losers. Psychology and Marketing, 15, 23-40.

Higgs, R.J. (1995). God in the stadium: Sports and religion in America. Lexington, KY: University Press of Kentucky.

Hirt, E.R., Zillmann, D., Erickson, G.A., \& Kennedy, C. (1992). Costs and benefits of allegiance: Changes in fans' self-ascribed competencies after team victory versus defeat. Journal of Personality and Social Psychology, 63, 724-738.

Hoffman, S.J. (Ed.). (1992). Sport and religion. Champaign, IL: Human Kinetics Publishers.

Holm, J.E., Beckwith, B.E., Ehde, D.M., \& Tinius, T.P. (1996). Cognitive-behavioral interventions for improving performance in competitive athletes: A controlled treatment outcome study. International Journal of Sport Psychology, 27, 463-475.

Idler, E.L. (1987). Religious involvement and the health of the elderly: Some hypotheses and an initial test. Social Forces, 66, 226-238.

Keyes, C.L.M. (1998). Social well-being. Social Psychology Quarterly, 61, 121-140.

Kimball, A., \& Freysinger, V.J. (2003). Leisure, stress, and coping: The sort participation of collegiate student-athletes. Leisure Sciences, 25, 115-141. 
Levin, J.S., Markides, K.S., \& Ray, L.A. (1996). Religious attendance and psychological well-being in Mexican Americans: A panel analysis of three-generations data. The Gerontologist, 36, 454-463.

List of Sports Attendance Figures. (2008). Retrieved February 28, 2008 from http:// en.wikipedia.org/wiki/List_of_sports_attendance_figures.

Lopiano, D.A. (1993). Political analysis: Gender equity strategies for the future. In G.L. Cohen (Ed.), Women in sport: Issues and controversies (pp. 104-116). Newbury Park, CA: Sage.

Luhtanen, R., \& Crocker, J. (1991). Self-esteem and intergroup comparison: Toward a theory of collective self-esteem. In J. Suls \& T.A. Wills (Eds.), Social comparisons: Contemporary theory and research (pp. 211-234). Hillsdale, NJ: Erlbaum.

Luhtanen, R., \& Crocker, J. (1992). A Collective Self-esteem Scale: Self-evaluation of one's social identity. Personality and Social Psychology Bulletin, 18, 302-318.

Richards, S., \& Aries, E. (1999). The Division III student-athlete: Academic performance, campus involvement, and growth. Journal of College Student Development, 40, 211218.

Rubin, M., \& Hewstone, M. (1998). Social identity theory's self-esteem hypothesis: A review and some suggestions for clarification. Personality and Social Psychology Review, 2, 40-62.

Russell, D., Peplau, L.A., \& Cutrona, C.E. (1980). The revised UCLA Loneliness Scale: Concurrent and discriminant validity evidence. Journal of Personality and Social Psychology, 39, 472-480.

Schurr, K.T., Wittig, A.F., Ruble, V.E., \& Henriksen, L.W. (1993). College graduation rates of student athletes and students attending college male basketball games: A case study. Journal of Sport Behavior, 16, 33-41.

Sedlacek, W.E., \& Adams-Gaston, J. (1992). Predicting academic success of student-athletes using SAT and noncognitive variables. Journal of Counseling and Development, 70, 724-727.

Wann, D.L. (1994). The "noble" sports fan: The relationships between team identification, self-esteem, and aggression. Perceptual and Motor Skills, 78, 864-866.

Wann, D.L. (2006a). Understanding the positive social psychological benefits of sport team identification: The Team Identification - Social Psychological Health Model. Group Dynamics. Theory, Research, and Practice, 10, 272-296.

Wann, D.L. (2006b). Examining the potential causal relationship between sport team identification and psychological well-being. Journal of Sport Behavior, 29, 79-95.

Wann, D.L. (2006c). The causes and consequences of sport team identification. In A.A. Raney \& J. Bryant (Eds.), Handbook of sports and media (pp. 331-352). Mahwah, NJ: Erlbaum.

Wann, D.L., \& Branscombe, N.R. (1993). Sports fans: Measuring degree of identification with the team. International Journal of Sport Psychology, 24, 1-17.

Wann, D.L., Dimmock, J.A., \& Grove, J.R. (2003). Generalizing the Team IdentificationPsychological Health Model to a different sport and culture: The case of Australian rules football. Group Dynamics. Theory, Research, and Practice, 7, 289-296.

Wann, D.L., \& Dolan, T.J. (1994a). Influence of spectators' identification on evaluation of the past present and future performance of a sports team. Perceptual and Motor Skills, 78, 547-552.

Wann, D.L., \& Dolan, T.J. (1994b). Spectators' evaluations of rival and fellow fans. The Psychological Record, 44, 351-358.

Wann, D.L., Dunham, M.D., Byrd, M.L., \& Keenan, B.L. (2004). The five-factor model of personality and the psychological health of highly identified sport fans. International Sports Journal, 8(2), 28-36. 
Wann, D.L., \& Grieve, F.G. (in press). The coping strategies of highly identified fans: The importance of team success on tendencies to utilize proactive pessimism. In L.W. Hugenberg, P. Haridakis, \& A. Earnheardt (Eds.), Media and mediated sports fandom. Jefferson, NC: McFarland.

Wann, D.L., Grieve, F.G., Waddill, P.J., \& Martin, J. (in press).Use of retroactive pessimism as a method of coping with identity threat: The impact of team identification. Group Processes \& Intergroup Relations.

Wann, D.L., Keenan, B., \& Page, L. (in press).Testing the Team Identification-Social Psychological Health Model: Examining non-marquee sports, seasonal differences, and multiple teams. Journal of Sport Behavior.

Wann, D.L., Inman, S., Ensor, C.L., Gates, R.D., \& Caldwell, D.S. (1999). Assessing the psychological well-being of sport fans using the Profile of Mood States: The importance of team identification. International Sports Journal, 3, 81-90.

Wann, D.L., Martin, J., Grieve, F.G., \& Gardner, L. (in press).Social connections at sporting events: Attendance and its positive relationship with state social psychological well-being. North American Journal of Psychology.

Wann, D.L., Melnick, M.J., Russell, G.W., \& Pease, D.G. (2001). Sport fans: The psychology and social impact of spectators. New York: Routledge Press.

Wann, D.L., \& Pierce, S. (2005). The relationship between sport team identification and social well- being: Additional evidence supporting the Team Identification-Social Psychological Health Model. North American Journal of Psychology, 7, 117-124.

Wann, D.L., \& Polk, J. (2007). The positive relationship between sport team identification and belief on the trustworthiness of others. North American Journal of Psychology, 9, 251-256.

Wann, D.L., Polk, J., \& Weaver, S. (2008, February). The Team Identification - Social Psychological Health Model: Gaining connections to others via sport team identification. Paper presented at the fourth annual Sport Psychology Gathering, Bowling Green, KY.

Wann, D.L., \& Robinson, T.R., III. (2002). The relationship between sport team identification and integration into and perceptions of a university. International Sports Journal, 6, 36-44.

Wann, D.L., \& Schrader, M.P. (2000). Controllability and stability in the self-serving attributions of sport spectators. The Journal of Social Psychology, 140, 160-168.

Wann, D.L., Walker, R.G., Cygan, J., Kawase, I., \& Ryan, J. (2005). Further replication of the relationship between team identification and psychological well-being: Examining non-classroom settings. North American Journal of Psychology, 7, 361-366.

Williamson, D.P., Zhang, J.J., Pease, D.G., \& Gaa, J.P. (2003). Dimensions of spectator identification associated with women's professional basketball game attendance. International Journal of Sport Management, 4, 59-91.

Witter, R.A., Stock, W.A., Okun, M.A., \& Haring, M.J. (1985). Religion and subjective well-being in adulthood: A quantitative synthesis. Review of Religious Research, 26, 332-342. 